\title{
THE IMPACT OF CHAIN EXTENDER ON THE PROPERTIES OF POLYURETHANE FOAM BASED ON RAPESEED OIL POLYOL OBTAINED VIA CHEMO-ENZYMATIC ROUTE
}

\author{
Agnè KAIRYTE், Saulius VAITKUS, Giedrius BALČIŪNAS \\ Laboratory of Thermal Insulating Materials, Scientific Institute of Thermal Insulation, \\ Vilnius Gediminas Technical University, Linkmenu g. 28, LT-08217 Vilnius, Lithuania
}

Received 02 May 2016; accepted 03 July 2016

\begin{abstract}
Presently, researches regarding green chemistry are conducted due to its significance for the mitigation of environmental problems, particularly those related to carbon dioxide emissions in relation to global warming and the usage of fossil feedstocks not only for energy generation but also for materials production. The study examines the impact of bio-products such as corn starch, rapeseed glycerin as well as petroleum based propylene glycol as bifunctional and trifunctional chain extenders on physical-mechanical properties of polyurethane foam from rapeseed oil polyol derived via chemo-enzymatic route. The obtained foams were characterized using European and international methodologies for determination of density, compressive strength perpendicular and parallel to foaming directions, thermal conductivity, long-term water absorption after 28 days of immersion, closed cell content and cell size. Foams containing (5-25) pphp of corn starch display significantly lower values in density and compressive strength as well as cell size compared to the neat polyurethane foam. The greatest compressive strength and the lowest thermal conductivity are obtained for foams with $25 \mathrm{pphp}$ of rapeseed glycerin. All foams extended with bio-products and propylene glycol are characterized by the higher long-term water absorption compared to that of the neat polyurethane foam.
\end{abstract}

Keywords: polyurethane foam, glycerin, starch, propylene glycol, renewable resources, chain extension, cross-linking.

\section{Introduction}

The concept of sustainable development as the development satisfying current demands of the society while not reducing the opportunities for further generations to fulfill their, was defined in 1987 by World Commission on Environment and Development (WCED 1987). Regarding the science of chemistry, EPA concluded the terminology which covered the most important principles of sustainability which are related to science of chemistry called Green chemistry. The main challenges for Green chemistry are to promote innovative chemistry technologies reducing the use and emission of hazardous materials during the design, modelling, manufacture or the use of chemical material, to develop and accept engineering decisions which reduce the consumption of energy, to reduce the use of resources and accumulation of wastes by implementing an effective catalysis processes and increasing the atom economy, as well as to use renewable resources and sub products obtainable from other, not limited areas.

The use of renewable resources for the synthesis of chemical materials reduces the negative impact on environment, e.g. the use of limited resources and emis-

Corresponding author:

A. Kairytė E-mail: agne.kairyte@vgtu.lt 
sion of gases causing greenhouse effect. Such resources open up opportunities for full or partial replacement of polymers from petroleum products which may compete or even surpass traditional materials on the basis of price, quality and impact on the environment (Belgacem, Gandini 2008; Alagi et al. 2016).

Annual production of vegetable oils (palm fruits, soybean, rapeseed/canola, sunflower, palm fruit seeds, olive, coconut) accounted for $175.7 \mathrm{mln}$. tones during the year 2014-2015. The production of these oils increased by $94 \%$ from 2000 to 2015 (Statista 2016). Oils are the excellent renewable resources for "green" chemical industry and especially for the application in polymers and their composites. Most of the oils do not have hydroxyl groups which are necessary to form urethane links with isocyanate, however, carbon-carbon double bonds and ester linkages are two major functional moieties present in vegetable oils structures that are used for chemical transformations into hydroxyl groups (Alagi et al. 2016) via different methods such as hydroformylation, transesterification or ozonolysis followed by hydrogenation and epoxidation with epoxy ring-opening (Ji et al. 2015) and chemo-enzymatic route. As to the latter method, in order to obtain polyols with hydroxyl number suitable for rigid polyurethane foams, the process is time consuming and the commercial enzymes are comparatively expensive. Therefore, the use of alternative lipase from a cheaper source could make chemo-enzymatic process more attractive (Šulcienè et al. 2014). Reducing the price, commercially available chain extenders having two or more functional groups may be used. The purpose of a chain extender in the synthesis of polyurethane (PU) foam is to improve the properties of the final product (Firdaus 2011). Most of the studies have been made on the effect determination of petroleum based chain extenders having bifunctional groups on properties of rigid PU foam (Rashmi et al. 2013; Pratondo et al. 2012; Firdaus 2012). Most of the cross linking agents and chain extenders for the production of PU foams are derived from petroleum. These agents can be produced from renewable resources as well, thus increasing the benefit for the environment. The purpose of this article is to investigate the effect of propylene glycol (PRG), rapeseed glycerine (GL) and corn starch (ST) on physical and mechanical properties of $\mathrm{PU}$ foams from rapeseed polyol obtained via chemo-enzymatic route.

\section{Experimental}

\subsection{Materials and methods}

Rapeseed oil based polyester polyol was obtained from JSC IMD Technologies (Vilnius, Lithuania). Lupranat M20S (31.5\% NCO), a 4,4'-diphenylmethane diisocyanate (MDI) having functionality of 2.7 , was received from BASF (Germany). Lupragen DMI and Lupragen N101 were received from BASF (Germany) and used as strong gelling and blowing catalysts. Tegostab B 1048 was used as a surfactant. It was received from Momentive (USA). Water was used as a chemical blowing agent. As chain extenders, PRG with moisture content of $0.2 \%$, GL from rapeseeds with moisture content of $0.5 \%$ and ST with moisture content of $11.4 \%$ were used as received.

Density of the foam with different amounts of chain extenders was measured on samples having the size of $(50 \times 50 \times 50) \mathrm{mm}$ according to EN 1602 . Compressive stress at $10 \%$ deformation or compressive strength up to $10 \%$ (hereinafter referred to as compressive strength) perpendicular and parallel to foaming directions were determined using specimens with dimension of $(50 \times 50 \times 50) \mathrm{mm}$ following the requirements of EN 826. Compression tests were performed using a computerized testing machine H10KS (Hounsfield, England). The cell morphology of the free rise direction specimens was observed using optical microscope. Software ImageJ was employed to determine average diameter of the cells.

Thermal conductivity was measured on specimens having the size of $(300 \times 300 \times 50) \mathrm{mm}$ using heat flow meter apparatus FOX 304 with a single-specimen symmetrical configuration and with the linear gradient guard for sample edges according to EN 12667 after 1 day after production. The size of specimens for the long-term water absorption after 28 days of total immersion was of $(50 \times 50 \times 50) \mathrm{mm}$, the parameter was determined in accordance with EN 12087 method 2A.

Scattering and interpretation of standard deviation of the results are obtained by evaluation of normality of the results and confidence intervals at $95 \%$ of confidence level according to:

$$
\bar{x}-\frac{t_{95 \%} \cdot S_{x}}{\sqrt{n}}<\bar{x}<\bar{x}+\frac{t_{95 \%} \cdot S_{x}}{\sqrt{n}},
$$

where: $n$ - number of tests; $t_{95 \%}-\mathrm{t}$-distribution at 95 $\%$ of confidence level (tabulated values); $S_{x}-$ standard deviation. 


\subsection{Preparation of extended PU foam}

Rapeseed polyol, blowing agent, surfactant and catalysts were mixed for 1 minute to produce an unfoamed blend of raw materials. Then, the obtained mixture was scaled and poured into 10 laboratory dishes. 1 dish was left for the preparation of the neat PU foam and 9 others for extended PU foams. Required amount (Table 1) of corresponding extender was scaled and mixed with the unfoamed blend of raw materials. Then, isocyanate was added and obtained mixture thoroughly mixed for another 10 seconds. After mixing, it was poured into an open mould having the size of $(400 \times 400 \times 100) \mathrm{mm}$. The foam was cured for 24 hours at ambient temperature and relative air humidity, respectively $(23 \pm 2){ }^{\circ} \mathrm{C}$ and $(50 \pm 5) \%$, before being removed.

\section{Results and discussion}

\subsection{Density and compressive strength}

Apparent density is an important parameter which can significantly influence various properties of PU foam, such as mechanical properties and water absorption
(Thirumal et al. 2008; Saint-Michel et al. 2006). The PU foam density and compressive strength perpendicular and parallel to foaming directions dependence on chain extender and its content is presented in Table 2. It can be observed that PU/PRG-5 foam has highly reduced density and compressive strength in all foaming directions comparing to the neat PU foam. This can be attributed to the increased blowing efficiency occurring due to increased mobility of the mixture as the molecular weight decreases (Lim et al. 2008). Since PRG is an extender having functionality equal to 2 , it is referred to as material increasing the content of soft domains, thus reducing the density of the obtained foams. The opposite conclusions have been made by Seo et al. (2003) who have used 1,4-butanediol as difunctional chain extender which results into increase in density and compressive strength.

Authors Pan, Saddler (2013) have observed that the addition of $3.5 \%$ by mass of glycerin reduced total density of PU foam by $9.7 \%$. PU/GL-5 and PU/GL15 foams are characterized by the same tendency, i.e. 5 pphp of GL have reduced PU density by $18.6 \%$ and

Table 1. The composition of rigid PU foam

\begin{tabular}{|c|c|c|c|c|}
\hline \multirow{2}{*}{ Component } & \multicolumn{3}{|c|}{ Amount of PRG, GL and ST, pphp $^{*}$} \\
\cline { 2 - 5 } & 0 & 5 & 15 & 25 \\
\hline Rapeseed oil polyol & 100 & 95 & 85 & 75 \\
Distilled water & 3 & 3 & 3 & 3 \\
Lupragen DMI & 1.8 & 1.8 & 1.8 & 1.8 \\
Lupragen N101 & 1.2 & 1.2 & 1.2 & 2 \\
Tegostab B 1048 $^{* *}$ & 2 & 2 & 2 & 2 \\
Isocyanate $^{* *}$ & \multicolumn{3}{|c|}{ Isocyanate index 125 } \\
\cline { 2 - 5 }
\end{tabular}

Notes: ${ }^{*}$ Parts per hundred polyol; ${ }^{* *}$ Moisture content of propylene glycol, rapeseed glycerin and corn starch was calculated into water amount needed to foam the specimens; ${ }^{* *}$ Hydroxyl numbers of chain extenders were taken into account when calculating the amount of isocyanate.

Table 2. Strength properties and density of extended PU foams

\begin{tabular}{|c|c|c|c|}
\hline Foam designation & Density, kg/m & \multicolumn{2}{|c|}{ Compressive strength, $\mathrm{kPa}$} \\
\cline { 3 - 4 } & & Perpendicular to foaming direction, $\mathrm{kPa}$ & Parallel to foaming direction, $\mathrm{kPa}$ \\
\hline Neat PU & $48.5 \pm 2.3$ & $194.2 \pm 5.5$ & $187.8 \pm 0.21$ \\
\hline \hline PU/PRG-5 & $38.4 \pm 1.5$ & $184.3 \pm 6.7$ & $99.01 \pm 1.5$ \\
\hline PU/PRG-15 & $42.1 \pm 1.6$ & $184.7 \pm 7.7$ & $161.4 \pm 3.7$ \\
\hline PU/PRG-25 & $42.4 \pm 0.53$ & $223.0 \pm 5.8$ & $165.9 \pm 2.5$ \\
\hline \hline PU/GL-5 & $39.5 \pm 0.98$ & $197.3 \pm 8.4$ & $124.5 \pm 1.5$ \\
\hline PU/GL-15 & $43.1 \pm 0.72$ & $238.0 \pm 7.2$ & $143.9 \pm 5.9$ \\
\hline PU/GL-25 & $51.1 \pm 1.9$ & $330.0 \pm 3.6$ & $165.9 \pm 5.3$ \\
\hline \hline PU/ST-5 & $41.0 \pm 1.3$ & $136.5 \pm 6.0$ & $119.5 \pm 4.1$ \\
\hline PU/ST-15 & $42.4 \pm 1.4$ & $151.6 \pm 7.8$ & $130.0 \pm 2.5$ \\
\hline PU/ST-25 & $46.6 \pm 2.4$ & $158.8 \pm 3.5$ & $144.6 \pm 5.3$ \\
\hline
\end{tabular}


15 pphp - by $11.1 \%$. The increase in density and compressive strength perpendicular to foaming direction when up to $25 \mathrm{pphp}$ of GL is used in PU/GL mixture can be observed due to higher cross-linking density when higher amount of GL is used. This might also be explained by increasing hydroxyl value which increases with the increase in GL. The obtained results show that the addition of GL reduces density only to a certain limit. Compressive strength parallel to foaming direction of PU/GL foams is highly reduced and it can be assumed that anisotropy index of PU/GL foams is much lower than that for the neat PU foam.

It is known, that biodegradable products based on starch exhibit some disadvantages, such as brittleness and poor mechanical characteristics. It is observed that ST filled foams' density and compressive strength in all directions have decreased compared to the neat $\mathrm{PU}$ foam. The addition of ST into polyol has reduced total hydroxyl value of PU/ST blend and higher molecular weight gives the PU/ST foams lower density due to low content of hard segments. The same tendencies of reducing densities while increasing the ST amount have been obtained by Alfani et al. (1998). However,the obtained results are contrary to the results obtained by Travinskaya et al. (2014) who have obtained PU/

a)

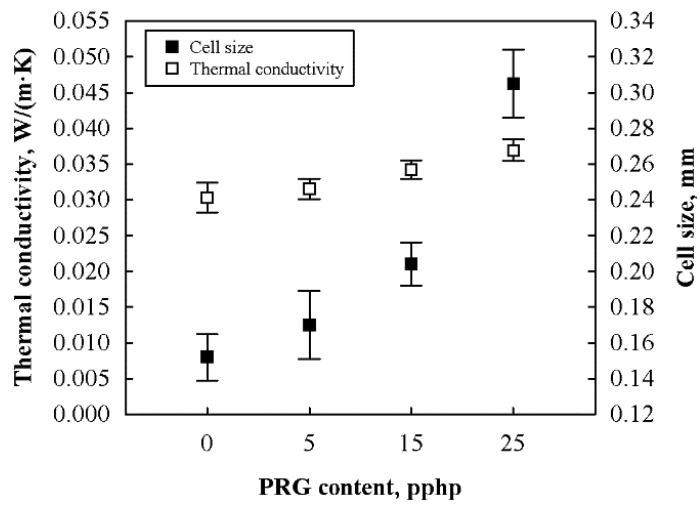

ST based films with better mechanical performance compared to the neat PU film. The authors claim that low ST content assures an optimal realization of intraand intermolecular hydrogen bonds which lead to the improvement of mechanical properties and that the higher amounts of ST have opposite effect.

Authors Desai et al. (2004) have noticed that ST act as crosslinking agent due to multiple hydroxyl functionality in the molecule and as results from Table 2 show, compressive strength both perpendicular and parallel to foaming directions increase with the increase in ST content from $5 \mathrm{pphp}$ to $25 \mathrm{pphp}$.

Compressive strength is highly dependent on the molecular weight of polyol mixture. The amount and stability of the hard segment determine the strength and stiffness of the foam (Zou et al. 2015). As the lowest density is obtained at PU/PRG-5, PU/GL-5 and PU/ST-5 compositions, the reduced compressive strength at all foaming directions is observed.

\subsection{Thermal conductivity and cell size}

The cell size is essential in controlling the mechanical and thermal insulating properties of PU foam. It can be observed from Figure 1a that increasing PRG and GL content from 5 pphp to $25 \mathrm{pphp}$, cell size in-

b)

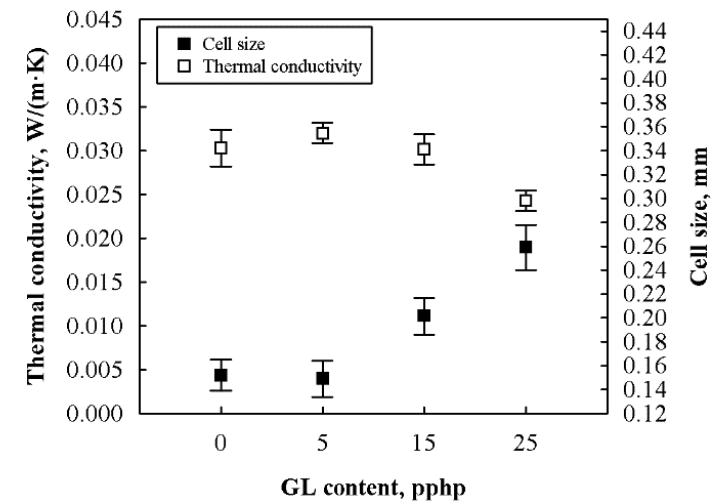

c)

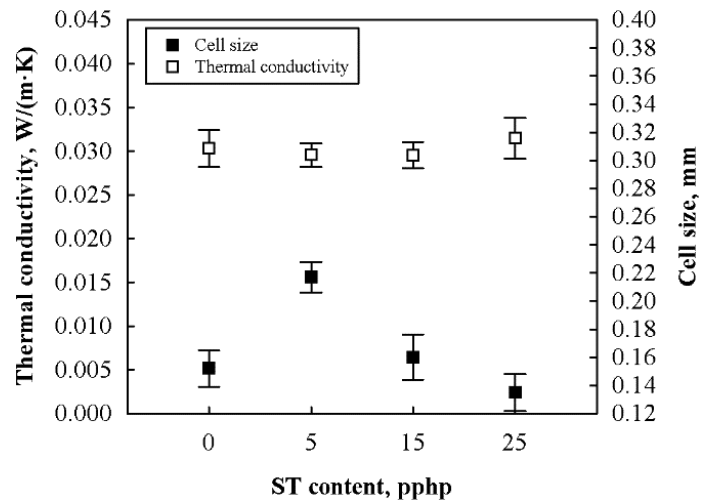

Fig. 1. Thermal conductivity and cell size of a) PU/PRG; b) PU/GL; c) PU/ST foams 
creases as well. A chemical blowing agent such as distilled water generates carbon dioxide through the chemical reaction with isocyanate accompanying the exothermic reaction heat. Because of the increase in temperature, the concentration of blowing gas in the mixture exceeds its limit of solubility, and the nucleation process of bubbles begins. The same results have been obtained by authors Thirumal et al. (2008) and Kwon et al. (2006) who have conducted a research, respectively, on foams blown with different contents of chemical blowing agent - water and foams obtained from liquefied starch polyol.

With the increase of PRG content, number of such bubbles formed increase and later they coalesce resulting in the increase in cell size. Even though the density (Table 2) is increasing in PU/PRG foams, the thermal conductivity increases as well. The same cell size results can be observed for PU/GL foams (Fig. 1b). Contrary to PU/PRG foams, PU/GL foams are characterized by the reducing thermal conductivity. It might be explained by the increasing density and, accordingly, decreasing radiant heat transfer via trapped gases in smaller foam cells in the higher density foams (Jeong, Jung 2015). As can be seen from Figure 1c, PU/ ST foams have almost the same thermal conductivity

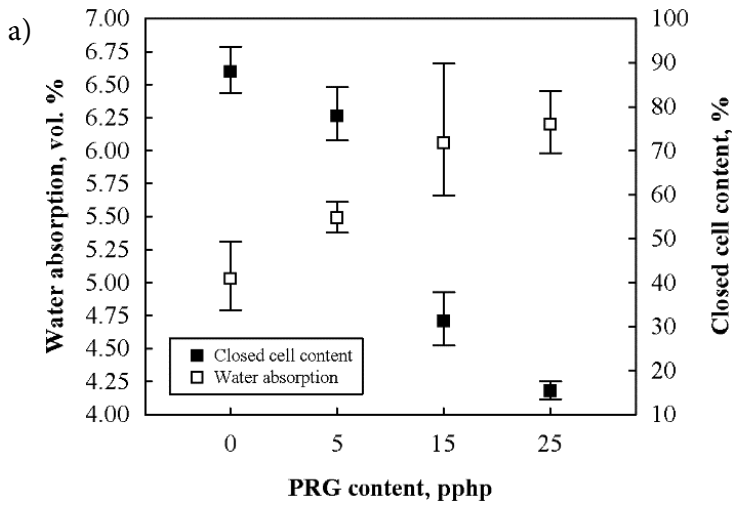

value independently from the ST content used. However, the cell size has reduced when from 15 pphp to 25 pphp of ST is added. ST is filler with the particle size of (4-5) $\mu \mathrm{m}$ and it may be stated that ST particles work as nucleating centers and induce a heterogeneous nucleating mechanism, thus producing a smaller cell size (Xu, Hanna 2007). However the opposite results (Kwon et al. 2006) have been obtained for foams where corn starch is used not as a filler but as a raw material for the preparation of polyol for biodegradable polyurethane foams.

\subsection{Long-term water absorption and closed cell content}

Figure 2 presents the results of long-term water absorption after 28 days of immersion and closed cell content for PRG, ST and GL modified PU foams. In rigid foams, where closed cells are desirable for most applications, the foam system must be balanced in such a way that the cell walls do not rupture at the point of maximum gas evolution.

It can be clearly seen (Fig. 2a) that PU/PRG foams are characterized by decreasing closed cell content with increasing amount of PRG from 5 pphp to 25 pphp, i.e. open cells create the path for water molecules to easily

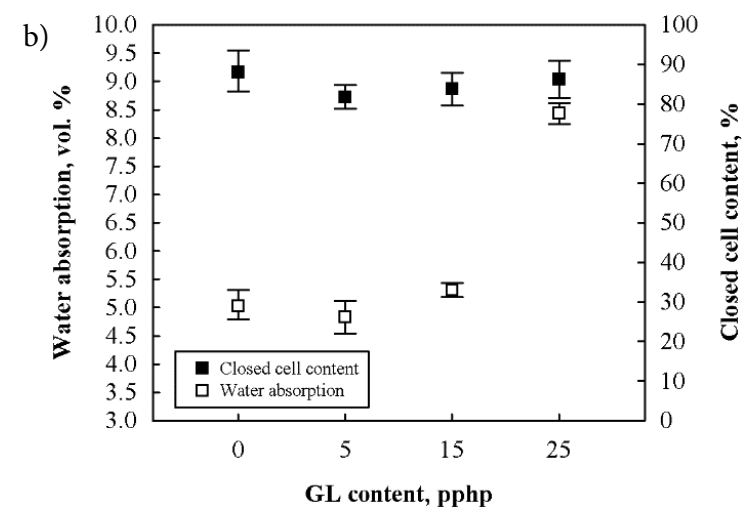

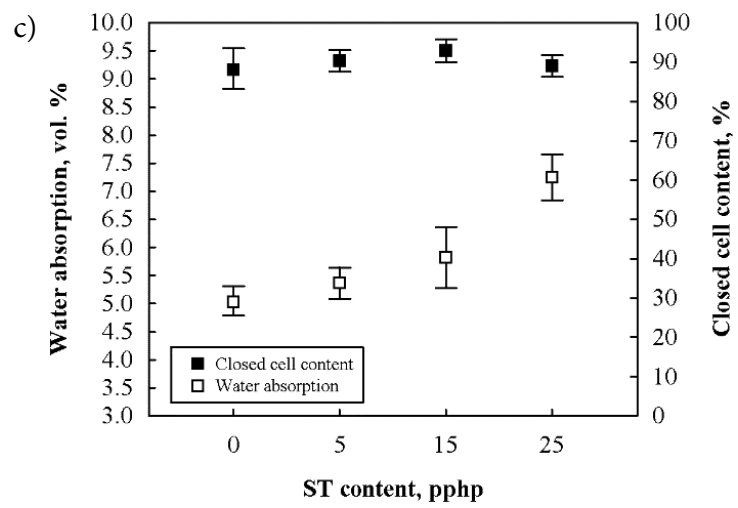

Fig. 2. Long-term water absorption and closed cell content of a) PU/PRG; b) PU/GL; c) PU/ST foams 
penetrate polyurethane foam structure. Long-term water absorption of PU/PRG foams when the maximum amount, i.e. $25 \mathrm{pphp}$, of PRG is used has increased by $\sim 1.2 \%$ compared to the neat PU foam. Even though closed cell content of PU/GL foams has reduced only slightly (Fig. 2(b)), the significant increase in water absorption can be observed, i.e. by $\sim 1.7 \%$.

Addition of GL from 5 pphp to 25 pphp increases cross-linking density which can be evident from the compressive strength results and it can be assumed that the ratio of hard to soft domains is higher; still the increased water absorption values might be explained by the hydrophilic nature of rapeseed GL.

Almost the same results of closed cell content for PU/ST foams can be observed from Figure $2 \mathrm{c}$ and this parameter does not have any impact on water absorbency of the final PU/ST foam. The increased water absorption from $5.0 \%$ to $7.3 \%$ when the content of ST from 5 pphp to 25 pphp is used, can be explained by increasing ratio of soft to hard segments which leads to a higher hydrophilicity in the polymer, since water was easily bridged to more urethane groups by hydrogen bonds (Huacuja-Sánchez et al. 2016) or with an increase of ST content some part of it segregates in a separate phase and forms a micro areas enriched with ST, therefore, the water absorption substantially increases (Travinskaya et al. 2014).

\section{Conclusions}

The range of density of obtained PRG, GL and ST extended PU foams is from $38.4 \mathrm{~kg} / \mathrm{m}^{3}$ to $51.1 \mathrm{~kg} / \mathrm{m}^{3}$ which is characteristic to traditional thermal insulating materials. The lowest and most favorable thermal conductivity is obtained for PU/GL foam extended with 25 pphp of GL and it is $0.0243 \mathrm{~W} /(\mathrm{m} \cdot \mathrm{K})$. Cell size measurements have shown that increasing amount of PRG and GL extender has increased the cell size, however, the PU/ST foam at 25 pphp has approx. 1.2 times lower cell size which leads to a conclusion that ST particles act as nucleating centers. Compared to the neat PU foam, the highest compressive strength perpendicular to foaming direction is observed for PU/PRG-25 foam.

PU foams have increased water absorption from $5.5 \%$ to $6.2 \%$ when the PRG content varies from 5 pphp to 25 pphp due to higher open cell content. The water absorption has also increased from $4.8 \%$ to $8.4 \%$ and from $5.4 \%$ to $7.3 \%$, respectively, for GL and ST extended foams at the content range from $5 \mathrm{pphp}$ to 25 pphp due to increased hydrophilicity of all systems.

\section{Recommendations}

The obtained densities of extended PU foams are similar of those for expanded and extruded polystyrenes and are favorable for application in thermal insulation. As carbon dioxide has high diffusivity, it is encouraged to coat obtained foams with aluminum foil in order to save foams from fast ageing. Notwithstanding the fact that all foams extended with PRG, GL and ST are characterized by lower compressive strength parallel to foaming direction and some of them by lower compressive strength perpendicular to foaming direction compared to that of the neat PU foam, the obtained values are higher than the minimum requirement of $100 \mathrm{kPa}$ for application as thermal insulating material. The issue of increased water absorption of PU/ ST foams may be reduced by modifying ST particles with silanes or titanates. Water absorption results have shown that PRG and GL extended foams are hydrophilic and cannot be used as foundation insulation, however, the obtained foams are favorable for the use as thermal insulating materials in building envelopes.

\section{Disclosure statement}

Authors declare that they do not have any competing financial, professional, or personal interests from other parties.

\section{References}

Alagi, P.; Choi, Y. J.; Hong, S. C. 2016. Preparation of vegetable oil-based polyols with controlled hydroxyl functionalities for thermoplastic polyurethane, European Polymer Journal 78: 46-60. http://dx.doi.org/10.1016/j.eurpolymj.2016.03.003

Alfani, R.; Iannacer, S.; Nicolais, L. 1998. Synthesis and characterization of starch-based polyurethane foams, Journal of Applied Polymer Science 68(5): 739-745.

http://dx.doi.org/10.1002/(SICI)1097-4628(19980502)68:5< 739::AID-APP6 $>3.0$

Belgacem, M. N.; Gandini, A. 2008. Monomers, polymers and composites from renewable resources. Amsterdam: Elsevier.

Desai, S.; Thakore, I. M.; Sarawade, B. D.; Devi, S. 2004. Structure-property relationship in polyurethane elastomers containing starch as a crosslinker, Polymer Engineering and Science 40(5): 1200-1210. http://dx.doi.org/10.1002/pen.11247

EN 826:2013. Thermal insulating products for building applications. Determination of compression behaviour. LSD 2013.13 p.

EN 1602:2013. Thermal insulating products for building applications. Determination of the apparent density. LSD 2013. 8 p.

EN 12087:2013. Thermal insulating products for building applications. Determination of long term water absorption by immersion. LSD 2013. 13 p.

EN 12667:2001. Thermal performance of building materials and products. Determination of thermal resistance by means of 
guarded hot plate and heat flow meter methods. Products of high and medium thermal resistance. LSD 2001. 53 p.

Firdaus, F. E. 2011. Chain extender on property relationships of polyurethane derived from soybean oil, International Journal of Chemical, Molecular, Nuclear, Materials and Metallurgical Engineering 5: 758-761.

Firdaus, F. E. 2012. The effect of ethylene glycol to soy polyurethane foam classifications, World Academy of Science, Engineering and Technology 6: 78-80.

Huacuja-Sánchez, J. E.; Müller, K.; Possart, W. 2016. Water diffusion in a crosslinked polyether-based polyurethane adhesive, International Journal of Adhesion and Adhesives 66: 167-175. http://dx.doi.org/10.1016/j.ijadhadh.2016.01.005

Ji, D.; Fang, Z.; He, W.; Luo, Z.; Jiang, X.; Wang, T.; Guo, K. 2015. Polyurethane rigid foams formed from different soybased polyols by the ring opening of epoxidised soybean oil with methanol, phenol, and cyclohexanol, Industrial Crops and Products 74: 76-82. http://dx.doi.org/10.1016/j.indcrop.2015.04.041

Jeong, Y. S.; Jung, H. K. 2015. Thermal performance analysis of reinforced concrete floor structure with radiant floor heating system in apartment housing, Advances in Materials Science and Engineering 2015: 1-7. http://dx.doi.org/10.1155/2015/367632

Kwon, O. J.; Yang, S. R.; Kim, D. H.; Park, J. S. 2006. Characterization of polyurethane foam prepared by using starch as polyol, Journal of Applied Polymer Science 103(3): 15441553. http://dx.doi.org/10.1002/app.25363

Lim, H.; Kim, S. H.; Kim, B. K. 2008. Effect of hydroxyl value of polyol in rigid polyurethane foams, Polymers for Advanced Technologies 19: 1729-1734. http://dx.doi.org/10.1002/pat.1188

Pan, X.; Saddler, J. N. 2013. Effect of replacing polyol by organosolv and kraft lignin on the property and structure of rigid polyurethane foam, Biotechnology for Biofuels 6(12): 1-10. http://dx.doi.org/10.1186/1754-6834-6-12.

Pratondo, E.; Hanggoro, A. W.; Ningrum, E. O.; Sumarno. 2012. Effects of chain extender to the structure of castor oil-based polyurethane foam, in Proceeding of International Conference on Chemical and Material Engineering, 12-13 September 2012, Semarang, Indonesia.

Rashmi, B. J.; Rusu, D.; Prashantha, K.; Lacrampe, M.F.; Krawczak, P. 2013. Development of bio-based thermoplastic poly- urethanes formulations using corn-derived chain extender for reactive rational molding, eXPRESS Polymer Letters 7: 852-862. http//dx.doi.org/10.3144/expresspolymlett.2013.82

Saint-Michel, F.; Chazeau, L.; Cavaillé, J. Y.; Chabert, E. 2006. Mechanical properties of high density polyurethane foams: I. Effect of the density, Composites Science and Technology 66: 2700-2708.

http://dx.doi.org/10.1016/j.compscitech.2006.03.009

Seo, W. J.; Jung, H. C.; Hyun, J. C.; Kim, W. N.; Lee, Y. B.; Choe, K. H.; Kim, S. B. 2003. Mechanical, morphological, and thermal properties of rigid polyurethane foams blown by distilled water, Journal of Applied Polymer Science 90(1): 12-20. http://dx.doi.org/10.1002/app.12238

Statista. 2016. Global vegetable oil production 2000-2015 [online], [cited 3 April 2016]. Available from Internet: http://www.statista.com/statistics/263978/global-vegetableoil-production-since-2000-2001/

Šulcienė, M.; Karalius, A.; Matijošyte, I. 2014. Chemo-enzymatic route for the production of biopolyol from rapeseed oil, Current Organic Chemistry 18: 3037-3043. http://dx.doi.org/10.2174/138527281823141212105146

Thirumal, M.; Khastgir, D.; Singha, N. K.; Manjunath, B. S.; Naik, Y. P. 2008. Effect of foam density on the properties of water blown rigid polyurethane foam, Journal of Applied Polymer Science 108: 1810-1817. http://dx.doi.org/ 10.1002/app.27712

Travinskaya, T.; Savelyev, Y.; Mishchuk, E. 2014. Waterborne polyurethane based starch containing materials: preparation, properties and study of degradability, Polymer Degradation and Stability 101: 102-108. http://dx.doi.org/10.1016/j.polymdegradstab.2013.12.006

World Commission on Environment and Development (WCED). 1987. Brundtland Report. Oslo, Norway.

Xu, B. Y.; Hanna, M. 2007. Effect of eggshell powder as nucleating agent on the structure, morphology and functional properties of normal corn starch foams, Packaging Technology and Science 20: 165-172. http://dx.doi.org/10.1002/pts.751

Zou, J.; Chen, Y.; Liang, M.; Zou, H. 2015. Effect of hard segments on the thermal and mechanical properties of water blown semi-rigid polyurethane foams, Journal of Polymer Research 22: 1-10. http://dx.doi.org/10.1007/s10965-015-0770-y

Agnè KAIRYTE் is a PhD student in Materials Engineering (08T) of Vilnius Gediminas Technical University, Scientific Institute of Thermal Insulation, Laboratory of Thermal Insulating Materials. Research interests: development and research of bio- and petroleum based polymeric materials and their composites.

Saulius VAITKUS is a senior scientist at Vilnius Gediminas Technical University, Scientific Institute of Thermal Insulation, Laboratory of Thermal Insulating Materials. Research interests: investigations of physical-mechanical and thermal-technical characteristics of thermal insulating materials and products; development and research of thermal insulation from local renewable resources, natural fibres.

Giedrius BALČIŪNAS is a senior engineer at Vilnius Gediminas Technical University, Scientific Institute of Thermal Insulation, Laboratory of Thermal Insulating Materials. Research interests: investigations of physical-mechanical properties of thermal insulating materials and products; development and research of hemp shives-based materials and their composites with different binders. 